\title{
The Study of the Growth of Escherichia coli on Pectins
}

\author{
Anatoly A. Shubakov, $\mathrm{PhD}^{1,2}$; Elena A. Mikhailova ${ }^{1 *}$ \\ ${ }^{I}$ Institute of Physiology of Komi Science Centre of the Ural Branch of the RAS, FRC Komi SC UB RAS \\ ${ }^{2}$ Institute of Biology of Komi Science Centre of the Ural Branch of the RAS, FRC Komi SC UB RAS \\ Syktyvkar, Komi Republic, the Russian Federation
}

\begin{abstract}
The growth of $E$. coli on pectins isolated from various plant sources was studied. We used commercial apple pectin AU701 and low-methyl esterified pectins (6-22\%) from callus cultures of tansy Tanacetum vulgare L. (TV, tanacetan), duckweed Lemna minor L. (LM, lemnan), and campion Silene vulgaris (M.) G. (SV, silenan). Bacterial growth was also tested on the enzymatic degradation products of tanacetan pectin. For comparison, bacterial growth was studied on easily metabolizable carbon sources - glucose and lactose. E. coli was cultivated on solid media in Petri dishes and in liquid nutrient media in Erlenmeyer flasks at a temperature of $+37^{\circ} \mathrm{C}$ and at room temperature. It was found that $E$. coli colonies do not form with growth on gels of tanacetan, lemnan and silenan. When growing on a gel of apple pectin, a weak bacterial growth is detected. However, E. coli is capable of growth on soluble products of enzymatic hydrolysis of tanacetan pectin - oligogalacturonides. (International Journal of Biomedicine. 2019;9(4):366-369.)
\end{abstract}

Key Words: Escherichia coli $\bullet$ liquid and solid nutrient media $\bullet$ pectin $\bullet$ pectin hydrolysis products $\bullet$ glucose $\bullet$ lactose

\section{Abbreviations}

AP, apple pectin; CaPGPs, calcium-pectic gel particles; CFU, colony forming units; PG-TV, products of hydrolysis of tanacetan; LM, pectin lemnan; SV, pectin silenan; MPA, meat-peptone agar; MPB, meat-peptone broth; MA, must agar; MM, mineral medium; SGF, simulated gastric fluid; SIF, simulated intestinal fluid; SCF, simulated colonic fluid.

\section{Introduction}

Escherichia coli, a gram-negative, non-sporulating facultative anaerobe, is a typical inhabitant of the lower intestines of endothermic animals and humans. ${ }^{(1)}$ Intestinal microbiota consists of more than 500 species of bacteria that make up $10^{10}-10^{11}$ cells per gram of colon contents. Although anaerobic bacteria in the intestines exceed the number of $E$. coli from 100:1 to 10000:1, E. coli is the dominant aerobic organism in the gastrointestinal tract of mammals. ${ }^{(2)}$

Most strains of E. coli are harmless mammalian commensals; however, some strains can cause intestinal or extra-intestinal diseases. ${ }^{(3)}$ The main function of the commensal flora in the intestine, especially in the colon, is

*Corresponding author: Elena A. Mikhailova. Institute of Physiology of Komi Science Centre of the Ural Branch of the RAS, FRC Komi SCUB RAS. Syktyvkar, Russia.E-mail: elkina@physiol.komisc.ru the fermentation of indigestible food residues and endogenous mucus produced by the epithelium..$^{(4)}$ In the digestive tract, commensal strains of $E$. coli are localized in the mucus layer covering the epithelial cells of the colon, adapting their metabolism in this ecological niche. ${ }^{(5)}$

The mucus gel layer of the gastrointestinal tract (mucin), synthesized and secreted by the goblet cells of the host, lubricates and protects the intestinal epithelium from damage caused by food and digestive secrets. The mucus gel layer also acts as a trap for microorganisms, including pathogens, preventing their access to the epithelium. ${ }^{(6)}$ Mucins of the intestinal mucosa are high molecular weight glycoproteins consisting of $80 \%$ carbohydrates and $20 \%$ protein. ${ }^{(7)}$

Although the intestines are usually considered anaerobic, the tissues surrounding the lumen are quite rich in oxygen and oxygen diffuses into the intestines and, in addition, oxygen is present in the swallowed air. That is, the intestines are not strictly anaerobic; therefore, the ability to have aerobic respiration provides $E$. coli with a great competitive advantage. ${ }^{(8)}$ 
Most carbohydrates in the colon are in the form of mucosal polysaccharides, which degrade with resident anaerobes that dominate the intestinal biota. ${ }^{(9)}$ Monosaccharides or disaccharides released from mucin and other mucosal glycoproteins support the growth of many intestinal bacteria such as $E$. coli, which do not form polysaccharide-degrading enzymes. ${ }^{(10)}$

In the literature, information on the growth characteristics of indigenous bacteria of the gastrointestinal tract of humans and animals, including E. coli, on pectic polysaccharides is quite limited and there are only few reports. ${ }^{(11,12)}$

The present work is devoted to the study of the growth of the gram-negative bacterium E. coli ARCIM B-8208 on pectins and products of their enzymatic hydrolysis.

\section{Materials and Methods}

\section{Object of study}

The object of the study was the gram-negative bacterium E. coli ARCIM B-8208. The culture was maintained on mowed MPA at a temperature of $+4^{\circ} \mathrm{C}$.

Conditions of cultivation of E. coli and conditions of cultivation of callus cultures

The seed was obtained by deep cultivation of $E$. coli for 2 days in Erlenmeyer flasks with a working volume of MPB of $200 \mathrm{ml}$ with stirring $(220 \mathrm{rpm})$ and a temperature of $+25^{\circ} \mathrm{C}$.

To study the growth characteristics, we studied deep cultivation of E. coli under static conditions in Erlenmeyer flasks with a working volume of $50 \mathrm{ml}$ of liquid nutrient medium both at a temperature of $+37^{\circ} \mathrm{C}$ and at room temperature.

The ability of $E$. coli to grow on solid media was studied in Petri dishes. The surface of the solid media was seeded with a suitably diluted bacterial inoculum and incubated at a temperature of $+37^{\circ} \mathrm{C}$.

Solid and liquid nutrient media were used in the experiments. Solid media: MPA, must agar (MA), solid media with different pectins. Liquid media: MPB, mineral medium (MM). The composition of the MPA: meat broth - $11, \mathrm{NaCl}$ $-5 \mathrm{~g} / \mathrm{l}$, peptone $-10 \mathrm{~g} / \mathrm{l}$, agar $-30 \mathrm{~g} / \mathrm{l}$. The composition of the MPB: meat broth - $11, \mathrm{NaCl}-5 \mathrm{~g} / \mathrm{l}$, peptone - $10 \mathrm{~g} / \mathrm{l}$. MM composition $(\mathrm{g} / \mathrm{l}): \mathrm{KH}_{2} \mathrm{PO}_{4}-0.25, \mathrm{NH}_{4} \mathrm{Cl}-0.5, \mathrm{MgSO}_{4}$. $7 \mathrm{H}_{2} \mathrm{O}-0.1, \mathrm{CaCl}_{2}-0.005, \mathrm{FeSO}_{4} \cdot 7 \mathrm{H}_{2} \mathrm{O}-0.005$.

The following pectins were used as difficult metabolizable carbon sources in solid or liquid nutrient media: low-methyl esterified commercial AP AU701 with a degree of methoxylation of $36 \%-44 \%$ and with the molecular weight of $406 \mathrm{kDa}$ (AP, Herbstreith \& Fox KG, Germany), lowmethyl esterified pectins (6-22\%) from callus cultures of tansy Tanacetum vulgare L. (TV), ${ }^{(13)}$ duckweed Lemna minor L. $(\mathrm{LM}),{ }^{(14)}$ and campion Silene vulgaris (M.) G. (SV) ${ }^{(15)}$ with a molecular mass of $>300 \mathrm{kDa}$. For comparison, E. coli was also cultivated in media with easily metabolizable carbon sources glucose and lactose.

Callus cultures of tansy, duckweed and campion were grown on modified Murashige and Skoog agar medium. ${ }^{(16)}$ The campion and duckweed callus cultures were cultivated with $1.0 \mathrm{mg} / \mathrm{l}$ of 2,4-dichlorophenoxyacetic acid (2,4-D) and $0.5 \mathrm{mg} / \mathrm{l}$ of 6-benzylaminopurine (BAP) added to the medium. The tansy callus was cultivated with the addition of 2,4-D $(1.5 \mathrm{mg} / \mathrm{l})+\mathrm{BAP}(0.5 \mathrm{mg} / \mathrm{l})$. The calluses were subcultured with an interval of 21 days (campion) and 28 days (tansy and duckweed) at the temperature of $26 \pm 1{ }^{\circ} \mathrm{C}$ in the dark. The callus tissue was frozen at the end of the cultivation. ${ }^{(17,18)}$ Pectins from callus cultures were isolated in the group of biotechnology of the Department of Molecular Immunology and Biotechnology of the Institute of Physiology.

\section{Formation of pectic gels and CaPGPS}

Pectic gels and spherical CaPGPs were obtained from AP and pectins of callus cultures in the presence of calcium ions by the method of ionotropic gelling. ${ }^{(19)}$

To obtain CaPGPs, pectins (30 mg) were dissolved in distilled water $(1 \mathrm{ml})$ by slow stirring with an MM-5 magnetic stirrer (Russia) for 2-5 hours at room temperature until complete dissolution.

Gel particles of spherical shape were prepared by drop-by-drop injection of the pectin solution $(3 \%)$ from a syringe through a needle with a hole diameter of $0.6 \mathrm{~mm}$ on a distance of $4-5 \mathrm{~cm}$ in the slowly stirred solution of calcium chloride $(0.34 \mathrm{M})$ and further stirring for 20 minutes at room temperature. The resulting gel particles were then washed three times in distilled water with stirring for 5 minutes and dried for $10-14$ hours at $+37^{\circ} \mathrm{C}$.

Obtaining products of enzymatic degradation of CaPGPS

An artificial gastrointestinal medium was used to obtain degradation products of CaPGPs.

The swelling and degradation of CaPGPs were studied under conditions simulating the gastrointestinal fluid, namely, SGF solution ( $\mathrm{pH}$ 1.25), SIF solution $(\mathrm{pH} 7.0)$ and SCF solution ( $\mathrm{pH}$ 7.0). The SGF medium was prepared with $\mathrm{NaCl}$ $(2.0 \mathrm{~g} / \mathrm{l}), \mathrm{KCl}(1.12 \mathrm{~g} / \mathrm{l}), \mathrm{KH}_{2} \mathrm{PO}_{4}(0.4 \mathrm{~g} / \mathrm{l})$ and $\mathrm{CaCl}_{2}(0.11$ $\mathrm{g} / \mathrm{l})$. The $\mathrm{pH}$ of the solution was adjusted to 1.25 by addition of $0.1 \mathrm{~N} \mathrm{HCl}$ solution. The SIF medium was prepared by addition of $1 \mathrm{~N} \mathrm{NaHCO}$ solution to the SGF solution to the $\mathrm{pH}$ value of 7.0. The SCF medium was prepared by addition of pectinase (Sigma, $1.18 \mathrm{U} / \mathrm{mg}$, USA) to the SIF solution. ${ }^{(20)}$ The concentration of pectinase in SCF medium was $1.7 \mathrm{mg} /$ $\mathrm{ml}(2.0 \mathrm{U} / \mathrm{ml})$.

$10 \mathrm{mg}$ of dry gel particles of tanacetan pectin were placed in Petri dishes (diameter $3.5 \mathrm{~cm}$ ) and subsequently incubated in $3 \mathrm{ml}$ of the SGF (2 h), SIF (4 h) and SCF (18 h) solutions with shaking on a shaker (Titramax 1000, Heidolph, Germany) at $100 \mathrm{rpm}$ and at $+37^{\circ} \mathrm{C}$. The enzymatic hydrolysis products of tanacetan pectin (PH-TV) obtained in SCF medium were used as a carbon source to study the growth of $E$. coli on them. Determination of growth parameters of E. coli

The optical density of $E$. coli suspensions during growth in liquid nutrient media was measured on an SF-103 spectrophotometer (Russia) at a wavelength of $660 \mathrm{~nm}$.

The ability to grow $E$. coli in solid media was evaluated by the number of CFU (colony forming unit) by the Koch method. Samples $(10 \mathrm{ml})$ were taken aseptically from bacterial suspensions and a series of 10 -fold dilutions were prepared. From the obtained dilutions, $50 \mu \mathrm{l}$ of aliquots of bacteria were sown on the surface of solid nutrient media. Petri dishes with crops were incubated at a temperature of $+37^{\circ} \mathrm{C}$. The grown colonies were counted on Days 1, 2, 3, 4, and 5 of incubation. 
The number of $\mathrm{CFU} / \mathrm{ml}$ was determined as the average of three replicates. Each experiment was carried out in three independent experiments.

When bacteria grew in liquid media with soluble carbon sources, the number of CFU in $1 \mathrm{ml}$ of bacterial suspensions was calculated using a calibration graph of the dependence of $\mathrm{CFU} / \mathrm{ml}$ on the optical density of the bacterial suspension $\left(\mathrm{OD}_{660}\right)$ (Fig. 1).

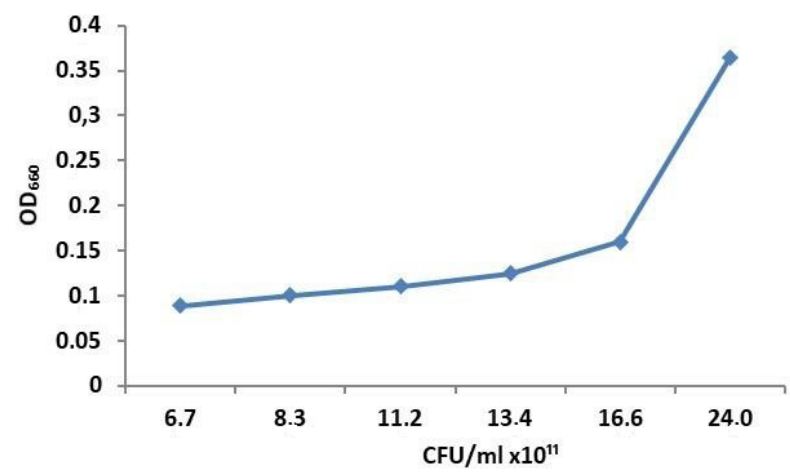

Fig. 1. Calibration graph of the dependence of $C F U / m l$ on $O D_{660}$ of bacterial suspension.

The statistical analysis was performed using the statistical software BioStat (version 4.03) and Microsoft Office Excell 2007. The mean (M) and standard deviation (SD) were calculated. A probability value of $P<0.05$ was considered statistically significant.

\section{Results and Discussion}

We studied the ability of the gram-negative bacterium E. coli ARCIM B-8208 to grow on the surface of solid pectincontaining media. Sources of pectins were commercial AP and the pectins tanacetan, lemnan, and silenan, isolated from callus cultures of tansy Tanacetum vulgare L., duckweed Lemna minor L. and campion Silene vulgaris (M.) G., respectively. Low methoxylated pectins, such as AP, tanacetan, lemnan, and silenan, form gels in the presence of calcium ions, and pectin molecules are cross-linked by calcium ions. ${ }^{(21)}$ For comparison, MPA and MA, the standard media for the cultivation of bacteria, were used as solid media. The ability of solid media to modulate the formation of $E$. coli biofilms was evaluated by the number of CFU.

The most active colony formation occurs with the growth of $E$. coli on MA and MPA (Fig.2).

After 5 days of growth on MA and MPA, the number of $E$. coli colonies was $(14.3 \pm 1.8) \times 10^{12}$ and $(13.0 \pm 2.6) \times 10^{12}$ $\mathrm{CFU} / \mathrm{ml}$, respectively. With growth on gel of $3 \% \mathrm{AP}$, the formation of $E$. coli colonies was observed, like on MPA and MA, also after 2 days of growth, but in a smaller amount, and after 5 days of cultivation on AP, the number of CFU $/ \mathrm{ml}$ was $(4.6 \pm 0.9) \times 10^{12}$. On the contrary, the formation of $E$. coli colonies did not occur with growth on $3 \%$ gels of tanacetan, lemnan and silenan. Thus, gels obtained from callus pectins did not modulate the formation of $E$. coli biofilms.

We studied the effect on the growth of E. coli of enzymatic hydrolysis products of CaPGPs obtained under artificial gastrointestinal conditions. CaPGPs were obtained from the pectin tanacetan polysaccharide isolated from callus of tansy Tanacetum vulgare $\mathrm{L}$.

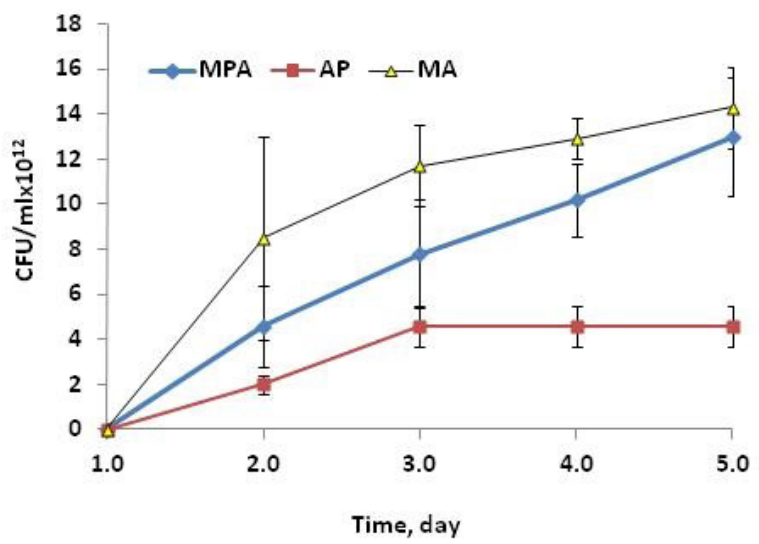

Fig. 2. Growth of E. coli on solid media.

The experiments were carried out under conditions of deep periodic cultivation in flasks, with stirring $(220 \mathrm{rpm})$ and without stirring (under static conditions) E. coli culture broths at room temperature. It was found that more active bacterial growth occurs under static conditions, without stirring, and the amount of $E$. coli after 6 days of growth in a liquid MM with $1 \%$ glucose was $(18.5 \pm 0.2) \times 10^{11} \mathrm{CFU} / \mathrm{ml}$ against $(13.2 \pm 0.1) \times 10^{11} \mathrm{CFU} / \mathrm{ml}$ with stirring (Fig.3).

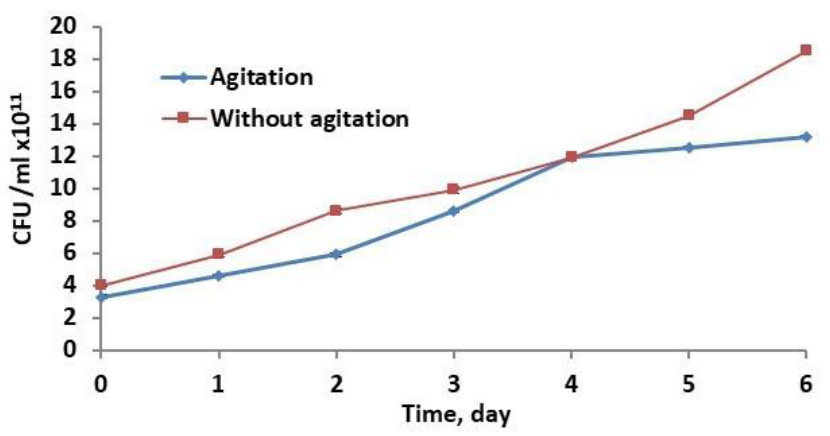

Fig. 3. Growth of E. coli in liquid mineral medium (MM) with $1 \%$ glucose.

We estimated the growth of $E$. coli in a liquid MM with both easily and hardly metabolizable carbon sources under static conditions at $+37^{\circ} \mathrm{C}$ (Fig.4). The most active growth of bacterium occurred in a mineral medium with easily metabolized carbon sources - lactose and glucose. The products of enzymatic hydrolysis of CaPGPs - oligogalacturonides obtained under conditions of an artificial gastrointestinal environment - contributed more to the growth of $E$. coli than did pectin tanacetan. The number of bacteria after 4 days of growth was $(43.5 \pm 0.6) \times 10^{11}$ and $(25.5 \pm 0.2) \times 10^{11} \mathrm{CFU} / \mathrm{ml}$, respectively.

Thus, the gels of tanacetan, lemnan, and silenan do not contribute to the growth of E. coli ARCIM B-8208. When growing on a gel of AP, a weak bacterial growth was 
detected. However, E. coli was capable of growth on soluble products of enzymatic hydrolysis of tanacetan pectin oligogalacturonides.

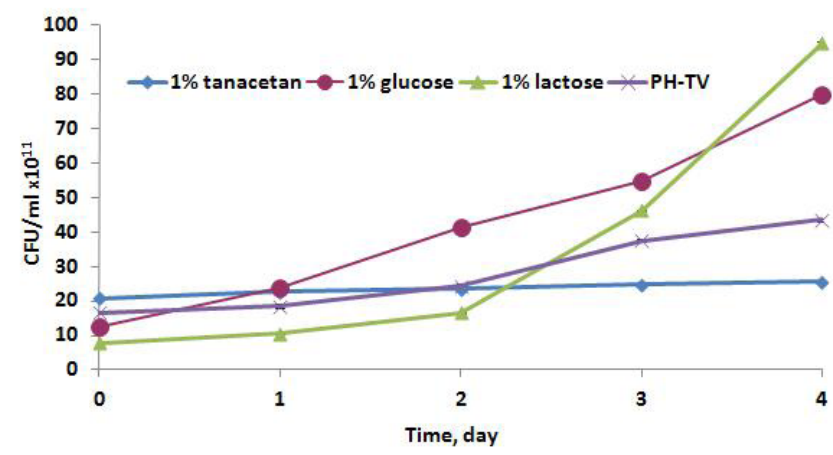

Fig. 4. Growth of E. coli in a liquid mineral medium with different carbon sources.

Apparently, in the colon, E. coli was also capable of growth on the products of enzymatic hydrolysis of pectins formed under the action of pectinases synthesized by the corresponding symbiotic microflora.

\section{Competing interests} interests.

The authors declare that they have no competing

\section{Sources of Funding}

The work was performed on the theme of research work (State registration number AAAA-A17-117012310147-8).

\section{Acknowledgments}

We express our gratitude to Dr. Elena Günter and Oksana Popeyko for kindly provided samples of pectins from callus cultures.

\section{References}

1. Berg RD. The indigenous gastrointestinal microflora. Trends Microbiol. 1996;4(11):430-5.

2. Tenaillon O, Skurnik D, Picard B, Denamur E. The population genetics of commensal Escherichia coli. Nat Rev Microbiol. 2010;8(3):207-17. doi:10.1038/nrmicro2298.

3. Ørskov F, Ørskov I. Escherichia coli serotyping and disease in man and animals. Can J Microbiol. 1992;38(7):699-704.

4. Guarner F, Malagelada JR. Gut flora in health and disease. Lancet. 2003;361(9345):512-9.

5. Poulsen LK, Lan F, Kristensen CS, Hobolth P, Molin S, Krogfelt KA. Spatial distribution of Escherichia coli in the mouse large intestine inferred from rRNA in situ hybridization. Infect Immun. 1994;62(11):5191-4.

6. Bertin Y, Chaucheyras-Durand F, Robbe-Masselot K,
Durand A, de la Foye A, Harel J, et al. Carbohydrate utilization by enterohaemorrhagic Escherichia coli O157:H7 in bovine intestinal content. Environ Microbiol. 2013;15(2):610-22. doi: 10.1111/1462-2920.12019.

7. Vakhrusheva TV, Baikova YP, Balabushevich NG, Gusev SA, Lomakina GY, Sholina EA, et al. Binding of Mucin by E. coli from Human Gut. Bull Exp Biol Med. 2018;165(2):235238. doi: 10.1007/s10517-018-4137-3.

8. Jones SA, Chowdhury FZ, Fabich AJ, Anderson A, Schreiner DM, House AL, et al. Respiration of Escherichia coli in the mouse intestine. Infect Immun. 2007;75(10):4891-9.

9. Chang DE, Smalley DJ, Tucker DL, Leatham MP, Norris WE, Stevenson SJ, et al. Carbon nutrition of Escherichia coli in the mouse intestine. Proc Natl Acad Sci USA. 2004;101(19):7427-32.

10. Markova JA, Anganova EV, Turskaya AL, Bybin VA, Savilov ED. [Regulation of Escherichia coli Biofilm Formation (Review)]. Prikl Biokhim Microbiol. 2018;54(1):3-15. doi: 10.7868/S05551099/8010014. [Article in Russian].

11. Werch SC, Jung RW, Day AA, Friedemann TE, Ivy AC. The decomposition of pectin and galacturonic acid by intestinal bacteria. J Infect Dis. 1942;70(3):231-242.

12. Dongowski G, Lorenz A, Anger H. Degradation of pectins with different degrees of esterification by Bacteroides thetaiotaomicron isolated from human gut flora. Appl Environ Microbiol. 2000;66(4):1321-7.

13. Paderin NM, Vityazev FV, Saveliev NYu, Markov PA, Mikhaylov VI, Patova OA, Popov SV. Effect of pectin of tansy, Tanacetum vulgare L., on feeding behaviour and food intake in mice. J Funct Foods. 2018;47:66-71. doi: 10.1016/j. jff.2018.05.040.

14. Golovchenko VV, Ovodova RG, Shashkov AS, Ovodov YuS. Structural studies of the pectic polysaccharide from duckweed Lemna minor L. Phytochemistry. 2002;60(1):89-97. 15. Gyunter EA, Ovodov YuS. [Pectic substances of callus culture Silene vulgaris (M.) G]. Prikl Biokhim Microbiol. 2011;47(1):90-94. [Article in Russian].

16. Murashige TA, Skoog S. Revised medium for rapid growth and bio assays with tobacco tissue cultures. Physiologia Plantarum. 1962;15(3):473-479.

17. Günter EA. [Preparation of callus cultures of Silene vulgaris (M.) G.]. Biotechnology. 2002;6:41-45. [Article in Russian].

18. Günter EA, Popeyko OV, Ovodov YuS. [Polysaccharides of Lemna minor L. cell lines]. Khim Tekhnol Rast Veshchestv. 2005;176:14-23. [Article in Russian].

19. Sriamornsak P, Nunthanid J. Calcium pectinate gel beads for controlled release drug delivery: I. Preparation and in vitro release studies. Int J Pharm. 1998;160:207-212.

20. Gebara C, Chaves KS, Ribeiro MCE, Souza FN, Grosso CRF, Gigante ML. Viability of Lactobacillus acidophilus La5 in pectin-whey protein microparticles during exposure to simulated gastrointestinal conditions. Food Res Int. 2013;51:872-878.

21. Günter EA, Popeyko OV. Calcium pectinate gel beads obtained from callus cultures pectins as promising systems for colon-targed drug delivery. Carbohydr Polym. 2016;147:490499. doi: 10.1016/j.carbpol.2016.04.026. 